\title{
Face masks effectively limit the probability of SARS-CoV-2 transmission
}

\author{
Yafang Cheng ${ }^{1 *}+$, Nan $\mathrm{Ma}^{2}+$, Christian Witt ${ }^{3}$, Steffen Rapp ${ }^{4}$, Philipp S. Wild ${ }^{4}$, Meinrat O. Andreae, ${ }^{1,5,6}$, Ulrich \\ Pöschl' ${ }^{1}$ Hang Su ${ }^{7,1 *}$ \\ ${ }^{1}$ Max Planck Institute for Chemistry, 55128 Mainz, Germany. ${ }^{2}$ Institute for Environmental and Climate Research, Jinan University, Guangzhou 511443, China. ${ }^{3}$ Department of \\ Outpatient Pneumology and Institute of Physiology, Charité Universitätsmedizin Berlin, Campus Charité Mitte, 10117 Berlin, Germany. ${ }^{4}$ University Medical Center of the \\ Johannes Gutenberg-University Mainz, 55131 Mainz, Germany. ${ }^{5}$ Scripps Institution of Oceanography, University of California San Diego, La Jolla, CA 92093, USA. \\ ${ }^{6}$ Department of Geology and Geophysics, King Saud University, 11451 Riyadh, Saudi Arabia. ${ }^{7}$ State Environmental Protection Key Laboratory of Formation and Prevention of \\ Urban Air Pollution Complex, Shanghai Academy of Environmental Sciences, Shanghai 200233, China. \\ ${ }^{*}$ Corresponding author. Email: h.su@mpic.de (H.S.); yafang.cheng@mpic.de (Y.C.)
}

†These authors contributed equally to this work.

Airborne transmission by droplets and aerosols is important for the spread of viruses. Face masks are a well-established preventive measure, but their effectiveness for mitigating SARS-CoV-2 transmission is still under debate. We show that variations in mask efficacy can be explained by different regimes of virus abundance and related to population-average infection probability and reproduction number. For SARSCoV-2, the viral load of infectious individuals can vary by orders of magnitude. We find that most environments and contacts are under conditions of low virus abundance (virus-limited) where surgical masks are effective at preventing virus spread. More advanced masks and other protective equipment are required in potentially virus-rich indoor environments including medical centers and hospitals. Masks are particularly effective in combination with other preventive measures like ventilation and distancing.

Airborne transmission is one of the main pathways for the transmission of respiratory viruses, including the severe acute respiratory syndrome coronavirus 2 (SARS-CoV-2) (1). Wearing face masks has been widely advocated to mitigate transmission. Masks are thought to protect people in two ways: source control reducing the emission and spread of respiratory viruses through airborne droplets and aerosols, and wearer protection reducing the inhalation of airborne respiratory viruses.

The effectiveness of masks, however, is still under debate. Compared to N95/FFP2 respirators which have very low particle penetration rates (around $\sim 5 \%$ ), surgical and similar masks exhibit higher and more variable penetration rates (around $\sim 30-70 \%)(2,3)$. Given the large number of particles emitted upon respiration and especially upon sneezing or coughing (4), the number of respiratory particles that may penetrate masks is substantial, which is one of the main reasons leading to doubts about their efficacy in preventing infections. Moreover, randomized clinical trials show inconsistent or inconclusive results, with some studies reporting only a marginal benefit or no effect of mask use (5, 6 ). Thus, surgical and similar masks are often considered to be ineffective. On the other hand, observational data show that regions or facilities with a higher percentage of the population wearing masks have better control of the coronavirus disease 2019 (COVID-19) (7-9). So how to explain these contrasting results and apparent inconsistencies?

Here, we develop a quantitative model of airborne virus exposure that can explain these contrasting results and provide a basis for quantifying the efficacy of face masks. We show that mask efficacy strongly depends on airborne virus abundance. Based on direct measurements of SARS-CoV-2 in air samples and population-level infection probabilities, we find that the virus abundance in most environments is sufficiently low for masks to be effective in reducing airborne transmission.

When evaluating the effectiveness of masks, we want to understand and quantify their effect on the infection probability, $P_{\text {inf. }}$ Assuming that every inhaled single virus (virion) has the same chance to infect a person, $P_{\text {inf }}$ can be calculated by a single-hit model of infection

$$
P_{\text {inf }}=1-\left(1-P_{\text {single }}\right)^{N_{\mathrm{v}}}
$$

where $P_{\text {single }}$ represents the infection probability for a single virus and $N_{\mathrm{v}}$ represents the total number of viruses to which the person is exposed (10). For airborne transmission, the infection probability $P_{\text {inf }}$ for a given time period can be plotted as a function of inhaled virus number, $N_{\mathrm{v}}$.

Figure 1 illustrates the dependence of $P_{\text {inf }}$ on $N_{\mathrm{v}}$ based on the single-hit model (Eq. 1) and scaled by the median infectious dose $\mathrm{ID}_{\mathrm{v}, 50}$ at which the probability of infection is $50 \%$ 
(10). It shows a highly nonlinear sensitivity of $P_{\text {inf }}$ to changes of $N_{\mathrm{v}}$. Accordingly, the same percentage change of $N_{\mathrm{v}}$ may lead to different changes in $P_{\text {inf }}$ depending on the absolute level of $N_{\mathrm{v}}$. In a virus-rich regime, where $N_{\mathrm{v}}$ is much higher than $\mathrm{ID}_{\mathrm{v}, 50}$ (Fig. 1, A and B), $P_{\text {inf }}$ is close to unity and not sensitive to changes of $N_{\mathrm{v}}$. In this case, wearing a mask may not suffice to prevent infection. In a virus-limited regime, where $N_{\mathrm{v}}$ is close to or lower than $\mathrm{ID}_{\mathrm{v}, 50}$, however, $P_{\text {inf }}$ strongly varies with $N_{\mathrm{v}}$, and reducing $N_{\mathrm{v}}$ by wearing a mask will lead to a substantial reduction in the infection probability (Fig. 1, C and $\mathrm{D}$ ). Thus, we need to determine the regime of airborne virus abundance to understand mask efficacy.

Respiratory particles, including aerosol particles and larger droplets, can carry viruses and are often used to visualize the transmission of airborne viruses (4). Taking a representative average of respiratory activity (11), we find that a person typically emits a total number of about $3 \times 10^{6}$ particles during a $30 \mathrm{~min}$ period (supplementary text, section S1.1). This very large number implies that indoor environments are usually in a respiratory particle-rich regime. Surgical masks with particle collection efficiencies around $\sim 50 \%$ cannot prevent the release of millions of particles per person and their inhalation by others (green dots in Fig. 1, B and D). In other words, the human-emitted respiratory particle number is so high that we cannot avoid inhaling particles generated by another person even when wearing a surgical mask. If every respiratory particle were to contain one or more viruses, indoor environments would often be in a virus-rich regime because the median infectious dose $\mathrm{ID}_{\mathrm{v}, 50}$ for respiratory diseases is typically of the order of a few tens to thousands of viruses $(12-14)$.

But does a respiratory particle-rich regime really imply a respiratory virus-rich regime? To answer this question, we investigated characteristic virus distributions in both exhaled air samples and indoor air samples including coronaviruses (HCoV-NL63, -OC43, -229E and -HKU1), influenza viruses (A and B), rhinoviruses and SARS-CoV-2 (supplementary text, section S1). We find that usually just a minor fraction of exhaled respiratory particles contains viruses. In contrast to the high number of emitted respiratory particles, the number of viruses in 30-min samples of exhaled air $\left(N_{\mathrm{v}, 30, \mathrm{ex}}\right)$ are typically low with mean values around $\sim 53$ for coronaviruses (HCoVNL63, -OC43, -229E and -HKU1), 38 for influenza viruses (A and B), and $\sim 96$ for rhinoviruses (11) (supplementary text, section S1.2, and Fig. 2). Figure 2, A and B, shows the infection probabilities obtained by inserting the number of exhaled viruses $\left(N_{\mathrm{v}, 30, \mathrm{ex}}\right)$ for the number of potentially inhaled viruses $\left(N_{\mathrm{v}, 30}\right)$ assuming a characteristic infectious dose of $\mathrm{ID}_{\mathrm{v}, 50}=100$ or 1000 , respectively (12-14). For SARS-CoV-2 in various medical centers, we obtained mean values of $N_{\mathrm{v}, 30}$ in the range of $\sim 1$ to $\sim 600$ (15-18) (supplementary text, section S1.3), which correspond to $P_{\text {inf }}$ values in the range of $\sim 0.1 \%$ to
$10 \%$ for $\mathrm{ID}_{\mathrm{v}, 50}=1000$ and $\sim 1 \%$ to $100 \%$ for $\mathrm{ID}_{\mathrm{v}, 50}=100$. The wide range of $N_{\mathrm{v}, 30} / \mathrm{ID}_{\mathrm{v}, 50}$ and $P_{\mathrm{inf}}$ values demonstrate that both virus-limited and virus-rich conditions can occur in indoor environments.

The high variabilities of $N_{\mathrm{v}, 30}$ and $P_{\text {inf }}$ shown in Fig. 2, A and $\mathrm{B}$, are consistent with the wide distribution of viral load observed in respiratory tract fluids (19) and need to be considered for estimating population-average infection probabilities, $P_{\text {inf,pop }}$ (supplementary text, section S4). For this purpose, we modeled $N_{\mathrm{v}}$ for SARS-CoV-2 as lognormally distributed with standard deviations $(\sigma)$ in the range of $\sim 1$ to 2 , based on recently reported distributions of the viral load of SARS-CoV2 in respiratory fluids (19) (supplementary text, section S4). As shown in Fig. 2C, the population-average infection probabilities with $\sigma>0$ are higher than in case of uniform exposure $(\sigma=0)$ in the virus-limited regime at $P_{\text {inf,pop }}<\sim 50 \%$. In other words: When the population-average infection probability is in the virus-limited regime with $P_{\text {inf,pop, } 0}<0.5$ (Fig. 2C), a broader distribution (larger $\sigma$ ) implies an increase in the fraction of transmission events under virus-rich conditions (e.g., super-spreader events), leading to a reduction of overall mask efficacy.

The basic reproduction number for COVID-19 $\left(R_{0} \approx 2-4\right.$; (20)) can be related to a basic population-average infection probability, $P_{\text {inf,pop, }, 0}$, through $R_{0}=P_{\text {inf,pop }, 0} \cdot c \cdot d(21)$. With the average duration of infectiousness ( $d \approx 10$ days), and average daily numbers of human contacts ( $c \approx 10$ to 25 per day) (22, 23 ), we obtain estimates in the range of $\sim 0.8 \%$ to $\sim 4 \%$ for $P_{\text {inf,pop,o, }}$ as indicated by the shaded area in Fig. 2 C. The low levels of $P_{\text {inf,pop,o }}$ indicate a widespread prevalence of viruslimited conditions.

Different regimes of abundance are relevant not only for the distinction of respiratory particles and viruses, but also for different types of viruses. For example, viruses with higher transmissibility, i.e., with higher loads and rates of emission/exhalation, greater environmental persistence, or lower $\mathrm{ID}_{\mathrm{v}, 50}$, may result in a virus-rich regime and lead to higher basic reproduction numbers as observed for measles and other highly infectious diseases. Our analysis shows that the levels of $P_{\text {inf }}$ and $R_{0}$ can vary widely for different viruses. This means that aerosol transmission does not necessarily lead to a measles-like high $R_{0}$, and that relatively low values of $P_{\text {inf }}$ and $R_{0}$ do not rule out airborne transmission. Based on the scaling with $\mathrm{ID}_{\mathrm{v}, 50}$, the curves shown in Figs. 1 to 3 can easily be applied to assess the efficacy of masks and other preventive measures against new and more infectious mutants of SARS-CoV-2 such as B.1.1.7.

Figure 3 illustrates how the efficacies of surgical masks and N95/FFP2 masks vary between virus-limited and virusrich conditions when masks are worn only by infectious persons (source control), only by susceptible persons (wearer protection), or by all persons (universal masking). In Fig. 3A, 
the population-average infection probability in case of surgical mask use $\left(P_{\text {inf,pop,mask }}\right)$ is plotted against the infection probability without masks $\left(P_{\text {inf,pop }}\right)$. It shows that surgical masking achieves large reductions in infection probability when the maskless infection probability is low, but increasingly smaller reductions when the maskless infection probability is high. Figure $3 \mathrm{~B}$ shows the corresponding mask efficacy, i.e., the percentage reduction of infection probability $\left(\triangle P_{\text {inf,pop }} / P_{\text {inf,pop }}\right.$ $\left.=\left(P_{\text {inf,pop }}-P_{\text {inf,pop,mask }}\right) / P_{\text {inf,pop }}\right)$, which decreases slowly with increasing $P_{\text {inf,pop }}$ in the virus-limited regime, exhibits a steep decrease upon transition into the virus-rich regime as $P_{\text {inf,pop }}$ approaches unity, and goes to zero at $P_{\text {inf,pop }}=1$. Figure $3, \mathrm{C}$ and D, shows equivalent plots for N95/FFP2 masks.

Figure 3 illustrates that source control alone is more effective than wearer protection alone, but that universal masking is the most effective. This is because masks are more effective in removing larger particles (Fig. 4) and freshly generated respiratory particles are usually largest at the source, shrinking upon evaporation in indoor air (20). Note that Fig. 3 accounts only for airborne transmission of viruses. When considering other forms of transmission, the relative importance of source control can be even higher (supplementary text, section S5) (20).

The nonlinear dependence of mask efficacy on infection risk differs from the assumption that the percentage change of infection probability due to mask use would be proportional to the percentage change of inhaled particle number (20). Under this assumption, wearing a mask would have the same impact on the transmission of a virus disease at any level of infection probability. Our analysis, however, shows that the efficacy of face masks depends strongly on the level of infection probability and virus abundance: masks reduce the infection probability by as much as their filter efficiency for respiratory particles in the virus-limited regime, but much less in the virus-rich regime (Fig. 3). Accordingly, experimental investigations may find low mask efficacies when they are performed under virus-rich conditions. Together with other influencing factors like consistent and correct mask use (supplementary text, section S7.3), changes between virusrich and virus-limited conditions may contribute to divergent results reported from laboratory studies and randomized controlled trials in different environments (20) (supplementary text, section S8). More importantly, the increasing effectiveness of mask use at low virus abundance implies synergistic effects of combining masks with other preventive measures that reduce the airborne virus concentration, such as ventilation and social distancing. For example, ventilation can change an environment from virus-rich to virus-limited conditions, which may be particularly important for medical centers with relatively high SARS-CoV-2 abundance (see Fig. 2 and supplementary text, section S6). On the other hand, not only the efficacy of face masks but also the efficacy of distancing may be reduced in virus-rich environments (supplementary text, section S6). The more measures are used, the more effective each measure will be in containing the virus transmission. If the inhaled dose may also affect the severity of infections (14), as currently debated (24), masks may still be useful even if the reduced dose still leads to an infection.

Figure 4 shows the size distribution of respiratory particles emitted by different human activities (25-27). Note that aerosols are physically defined as airborne solid or liquid particles with diameters smaller than $100 \mu \mathrm{m}$, which can remain suspended over extended periods of time. In medical studies, however, a threshold diameter of $5 \mu \mathrm{m}$ has often been used to distinguish between a so-called "aerosol mode" and a "droplet mode". Our analysis of measurement data from exhaled and ambient air samples indicates that the so-called "aerosol mode" $(<5 \mu \mathrm{m})$ contains more viruses than the socalled "droplet mode" (>5 $\mu \mathrm{m})$ (11), although the latter comprises a larger volume of liquid emitted from the respiratory tract (tables S1 and S2). This may be explained by the following mechanisms: a higher viral load occurring in the lower respiratory tract where the smaller aerosol particles are generated (28); or an enrichment of organic surfactants and viruses upon generation of smaller aerosol particles (29). Enrichment of viruses in the aerosol mode can enhance their transmission because smaller particles remain suspended for a longer time, leading to stronger accumulation and dispersion in the air. This may cause higher airborne virus concentrations, inhaled virus numbers, and infection risks especially in densely occupied rooms with poor ventilation and long periods of exposure. Moreover, small aerosol particles have a higher penetration rate and higher probability of reaching the lower respiratory tract (figs. S5 and S6).

Our analysis was focused on respiratory particles and droplets with diameters smaller than $100 \mu \mathrm{m}$ (traditional physical definition of aerosols (30)). Because of rapid gravitational settling, respiratory droplets larger than $100 \mu \mathrm{m}$ are removed from the air within seconds, but they may still reach the upper respiratory tract of persons in close contact and cause infections by carrying large numbers of viruses in their very large liquid volume. For example, a single one-millimeter droplet may carry as many as $\sim 50,000$ viruses in case of a viral load of $10^{8}$ per milliliter respiratory fluid, which is realistic and higher than the estimated infectious dose for SARSCoV-2 (14). Such large droplets, however, are very efficiently $(\sim 100 \%)$ removed even by simple masks (Fig. 4 and supplementary text, section S3), further emphasizing the importance and efficacy of face masks for preventing infections. Because of the strong size dependence and to avoid ambiguities, we suggest that diameter range should be explicitly specified when discussing airborne transmission by fine respiratory aerosol particles or larger droplets. 
Our results have important implications for understanding and communicating preventive measures against the transmission of airborne viruses including SARS-CoV-2. When people see images or videos of millions of respiratory particles exhaled by talking or coughing, they may be afraid that simple masks with limited filtration efficiency (e.g., 30$70 \%)$ cannot really protect them from inhaling these particles. However, as only few respiratory particles contain viruses and most environments are in a virus-limited regime, wearing masks can indeed keep the number of inhaled viruses in a low $P_{\text {inf }}$ regime and explain the observed efficacy of face masks in preventing the spread of COVID-19. However, unfavorable conditions and the large variability of viral loads may lead to a virus-rich regime in certain indoor environments, such as medical centers treating COVID-19 patients. In such environments, high efficiency masks and further protective measures like efficient ventilation should be used to keep the infection risk low. The nonlinear dependence of mask efficacy on airborne virus concentration, i.e., the higher mask efficacy at lower virus abundance, also highlights the importance of combining masks with other preventive measures. Effective ventilation and social distancing will reduce ambient virus concentrations and increase the effectiveness of face masks in containing the virus transmission. Moreover, high compliance and correct use of masks is important to ensure the effectiveness of universal masking in reducing the reproduction number (supplementary text, section S7.3, and fig. S11) (20).

\section{REFERENCES AND NOTES}

1. L. Morawska, D. K. Milton, It is time to address airborne transmission of coronavirus disease 2019 (COVID-19). Clin. Infect. Dis. 71, 2311-2313 (2020). doi:10.1093/cid/ciaa939 Medline

2. S. A. Grinshpun, H. Haruta, R. M. Eninger, T. Reponen, R. T. McKay, S.-A. Lee, Performance of an N95 filtering facepiece particulate respirator and a surgical mask during human breathing: Two pathways for particle penetration. J. Occup. Environ. Hyg. 6, 593-603 (2009). doi:10.1080/15459620903120086 Medline

3. T. Oberg, L. M. Brosseau, Surgical mask filter and fit performance. Am. J. Infect. Control 36, 276-282 (2008). doi:10.1016/i.ajic.2007.07.008 Medline

4. L. Bourouiba, Turbulent gas clouds and respiratory pathogen emissions: Potential implications for reducing transmission of COVID-19. JAMA 323, 1837-1838 (2020). doi:10.1001/jama.2020.4756 Medline

5. A. E. Aiello, G. F. Murray, V. Perez, R. M. Coulborn, B. M. Davis, M. Uddin, D. K. Shay, S. H. Waterman, A. S. Monto, Mask use, hand hygiene, and seasonal influenza-like illness among young adults: A randomized intervention trial. J. Infect. Dis. 201, 491-498 (2010). doi:10.1086/650396 Medline

6. H. Bundgaard, J. S. Bundgaard, D. E. T. Raaschou-Pedersen, C. von Buchwald, T. Todsen, J. B. Norsk, M. M. Pries-Heje, C. R. Vissing, P. B. Nielsen, U. C. Winsløw, K. Fogh, R. Hasselbalch, J. H. Kristensen, A. Ringgaard, M. Porsborg Andersen, N. B. Goecke, R. Trebbien, K. Skovgaard, T. Benfield, H. Ullum, C. Torp-Pedersen, K. Iversen, Effectiveness of adding a mask recommendation to other public health measures to prevent SARS-CoV-2 infection in Danish mask wearers: A randomized controlled trial. Ann. Intern. Med. 174, 335-343 (2021). doi:10.7326/M20-6817 Medline

7. D. K. Chu, E. A. Akl, S. Duda, K. Solo, S. Yaacoub, H. J. Schünemann, COVID-19 Systematic Urgent Review Group Effort (SURGE) study authors, Physical distancing, face masks, and eye protection to prevent person-to-person transmission of SARS-CoV-2 and COVID-19: A systematic review and meta- analysis. Lancet 395, 1973-1987 (2020). doi:10.1016/S0140-6736(20)31142-9 Medline

8. R. Zhang, Y. Li, A. L. Zhang, Y. Wang, M. J. Molina, Identifying airborne transmission as the dominant route for the spread of COVID-19. Proc. Natl. Acad. Sci. U.S.A. 117, 14857-14863 (2020). doi:10.1073/pnas.2009637117 Medline

9. J. T. Brooks, J. C. Butler, R. R. Redfield, Universal masking to prevent SARS-CoV-2 transmission-The time is now. JAMA 324, 635-637 (2020). doi:10.1001/iama.2020.13107 Medline

10. C. N. Haas, J. B. Rose, C. P. Gerba, Quantitative Microbial Risk Assessment (Wiley, 2014).

11. N. H. L. Leung, D. K. W. Chu, E. Y. C. Shiu, K.-H. Chan, J. J. McDevitt, B. J. P. Hau, H.-L. Yen, Y. Li, D. K. M. Ip, J. S. M. Peiris, W.-H. Seto, G. M. Leung, D. K. Milton, B. J. Cowling, Respiratory virus shedding in exhaled breath and efficacy of face masks. Nat. Med. 26, 676-680 (2020). doi:10.1038/s41591-020-0843-2 Medline

12. T. Watanabe, T. A. Bartrand, M. H. Weir, T. Omura, C. N. Haas, Development of a dose-response model for SARS coronavirus. Risk Anal. 30, 1129-1138 (2010). doi:10.1111/i.1539-6924.2010.01427 x Medline

13. A. Roberts, L. Vogel, J. Guarner, N. Hayes, B. Murphy, S. Zaki, K. Subbarao, Severe acute respiratory syndrome coronavirus infection of golden Syrian hamsters. J. Virol. 79, 503-511 (2005). doi:10.1128/JVI.79.1.503-511.2005 Medline

14. M. Imai, K. Iwatsuki-Horimoto, M. Hatta, S. Loeber, P. J. Halfmann, N. Nakajima, T. Watanabe, M. Ujie, K. Takahashi, M. Ito, S. Yamada, S. Fan, S. Chiba, M. Kuroda, L. Guan, K. Takada, T. Armbrust, A. Balogh, Y. Furusawa, M. Okuda, H. Ueki, A. Yasuhara, Y. Sakai-Tagawa, T. J. S. Lopes, M. Kiso, S. Yamayoshi, N. Kinoshita, N. Ohmagari, S. I. Hattori, M. Takeda, H. Mitsuya, F. Krammer, T. Suzuki, Y. Kawaoka, Syrian hamsters as a small animal model for SARS-CoV-2 infection and countermeasure development. Proc. Natl. Acad. Sci. U.S.A. 117, 16587-16595 (2020). doi:10.1073/pnas.2009799117 Medline

15. P. Y. Chia, K. K. Coleman, Y. K. Tan, S. W. X. Ong, M. Gum, S. K. Lau, X. F. Lim, A. S. Lim, S. Sutjipto, P. H. Lee, T. T. Son, B. E. Young, D. K. Milton, G. C. Gray, S. Schuster, T. Barkham, P. P. De, S. Vasoo, M. Chan, B. S. P. Ang, B. H. Tan, Y.-S. Leo, O.-T. Ng, M. S. Y. Wong, K. Marimuthu; Singapore 2019 Novel Coronavirus Outbreak Research Team, Detection of air and surface contamination by SARSCoV-2 in hospital rooms of infected patients. Nat. Commun. 11, 2800 (2020). doi:10.1038/s41467-020-16670-2 Medline

16. J. L. Santarpia, D. N. Rivera, V. L. Herrera, M. J. Morwitzer, H. M. Creager, G. W. Santarpia, K. K. Crown, D. M. Brett-Major, E. R. Schnaubelt, M. J. Broadhurst, J. V. Lawler, S. P. Reid, J. J. Lowe, Aerosol and surface contamination of SARS-CoV-2 observed in quarantine and isolation care. Sci. Rep. 10, 12732 (2020). doi:10.1038/s41598-020-69286-3

17. J. A. Lednicky, S. N. Shankar, M. A. Elbadry, J. C. Gibson, M. M. Alam, C. J. Stephenson, A. Eiguren-Fernandez, J. G. Morris, C. N. Mavian, M. Salemi, J. R. Clugston, C.-Y. Wu, Collection of SARS-CoV-2 virus from the air of a clinic within a university student health care center and analyses of the viral genomic sequence. Aerosol Air Qual. Res. 20, 1167-1171 (2020). doi:10.4209/aaqr.2020.05.0202 Medline

18. Y. Liu, Z. Ning, Y. Chen, M. Guo, Y. Liu, N. K. Gali, L. Sun, Y. Duan, J. Cai, D. Westerdahl, X. Liu, K. Xu, K. F. Ho, H. Kan, Q. Fu, K. Lan, Aerodynamic analysis of SARS-CoV-2 in two Wuhan hospitals. Nature 582, 557-560 (2020). doi:10.1038/s41586-020-2271-3 Medline

19. D. Jacot, G. Greub, K. Jaton, O. Opota, Viral load of SARS-CoV-2 across patients and compared to other respiratory viruses. Microbes Infect. 22, 617-621 (2020). doi:10.1016/i.micinf.2020.08.004 Medline

20. J. Howard, A. Huang, Z. Li, Z. Tufekci, V. Zdimal, H.-M. van der Westhuizen, A. von Delft, A. Price, L. Fridman, L.-H. Tang, V. Tang, G. L. Watson, C. E. Bax, R. Shaikh, F. Questier, D. Hernandez, L. F. Chu, C. M. Ramirez, A. W. Rimoin, An evidence review of face masks against COVID-19. Proc. Natl. Acad. Sci. U.S.A. 118, e2014564118 (2021). doi:10.1073/pnas.2014564118 Medline

21. P. van den Driessche, J. Watmough, in Mathematical Epidemiology, F. Brauer, P. van den Driessche, J. Wu, Eds. (Springer, 2008), pp. 159-178.

22. M. A. Johansson, T. M. Quandelacy, S. Kada, P. V. Prasad, M. Steele, J. T. Brooks, R. B. Slayton, M. Biggerstaff, J. C. Butler, SARS-CoV-2 transmission from people without COVID-19 symptoms. JAMA Netw. Open 4, e2035057 (2021). doi:10.1001/jamanetworkopen.2020.35057 Medline

23. J. Zhang, M. Litvinova, Y. Liang, Y. Wang, W. Wang, S. Zhao, Q. Wu, S. Merler, C. 
Viboud, A. Vespignani, M. Ajelli, H. Yu, Changes in contact patterns shape the dynamics of the COVID-19 outbreak in China. Science 368, 1481-1486 (2020). doi:10.1126/science abb8001 Medline

24. A. L. Rasmussen, K. Escandón, S. V. Popescu, Facial masking for Covid-19. N. Engl. J. Med. 383, 2092-2094 (2020). doi:10.1056/NEJMc2030886 Medline

25. C. Y. H. Chao, M. P. Wan, L. Morawska, G. R. Johnson, Z. D. Ristovski, M. Hargreaves, K. Mengersen, S. Corbett, Y. Li, X. Xie, D. Katoshevski, Characterization of expiration air jets and droplet size distributions immediately at the mouth opening. J. Aerosol Sci. 40, 122-133 (2009). doi:10.1016/i.jaerosci.2008.10.003 Medline

26. J. P. Duguid, The size and the duration of air-carriage of respiratory droplets and droplet-nuclei. Epidemiol. Infect. 44, 471-479 (1946). doi:10.1017/S0022172400019288 Medline

27. H. Holmgren, E. Ljungström, A.-C. Almstrand, B. Bake, A.-C. Olin, Size distribution of exhaled particles in the range from 0.01 to $2.0 \mu \mathrm{m}$. J. Aerosol Sci. 41, 439-446 (2010). doi:10.1016/.j.jaerosci.2010.02.011

28. B. Bake, P. Larsson, G. Ljungkvist, E. Ljungström, A. C. Olin, Exhaled particles and small airways. Respir. Res. 20, 8 (2019). doi:10.1186/s12931-019-0970-9 Medline

29. S. M. Burrows, O. Ogunro, A. A. Frossard, L. M. Russell, P. J. Rasch, S. M. Elliott, A physically based framework for modeling the organic fractionation of sea spray aerosol from bubble film Langmuir equilibria. Atmos. Chem. Phys. 14, 1360113629 (2014). doi:10.5194/acp-14-13601-2014

30. K. A. Prather, L. C. Marr, R. T. Schooley, M. A. McDiarmid, M. E. Wilson, D. K. Milton, Airborne transmission of SARS-CoV-2. Science 370, 303-304 (2020). doi:10.1126/science.abf0521 Medline

31. H. Su, Face masks effectively limit the probability of SARS-CoV-2 transmission [data set], version 1.0, Open Research Data Repository of the Max Planck Society (2021); https://dx.doi.org/10.17617/3.5d.

32. W. C. Hinds, Aerosol Technology: Properties, Behavior, and Measurement of Airborne Particles (Wiley, 1999).

33. P. A. Baron, K. Willeke, Eds., Aerosol Measurement: Principles, Techniques, and Applications (Wiley, 2005).

34. J. H. Seinfeld, S. N. Pandis, Atmospheric Chemistry and Physics: From Air Pollution to Climate Change (Wiley, 2006).

35. M. O. Fernandez, R. J. Thomas, N. J. Garton, A. Hudson, A. Haddrell, J. P. Reid, Assessing the airborne survival of bacteria in populations of aerosol droplets with a novel technology. J. R. Soc. Interface 16, 20180779 (2019). doi:10.1098/rsif.2018.0779 Medline

36. M. Nicas, W. W. Nazaroff, A. Hubbard, Toward understanding the risk of secondary airborne infection: Emission of respirable pathogens. J. Occup. Environ. Hyg. 2, 143-154 (2005). doi:10.1080/15459620590918466 Medline

37. M. Landers, G. Barker, S. Wallentine, J. W. McWhorter, C. Peel, A comparison of tidal volume, breathing frequency, and minute ventilation between two sitting postures in healthy adults. Physiother. Theory Pract. 19, 109-119 (2003). doi:10.1080/09593980307958

38. J. Lelieveld, F. Helleis, S. Borrmann, Y. Cheng, F. Drewnick, G. Haug, T. Klimach, J. Sciare, H. Su, U. Pöschl, Model calculations of aerosol transmission and infection risk of COVID-19 in indoor environments. Int. J. Environ. Res. Public Health 17, 8114 (2020). doi:10.3390/ijerph17218114 Medline

39. N. van Doremalen, T. Bushmaker, D. H. Morris, M. G. Holbrook, A. Gamble, B. N. Williamson, A. Tamin, J. L. Harcourt, N. J. Thornburg, S. I. Gerber, J. O. LloydSmith, E. de Wit, V. J. Munster, Aerosol and surface stability of SARS-CoV-2 as compared with SARS-CoV-1. N. Engl. J. Med. 382, 1564-1567 (2020). doi:10.1056/NEJMc2004973 Medline

40. A. C. K. Lai, W. W. Nazaroff, Modeling indoor particle deposition from turbulent flow onto smooth surfaces. J. Aerosol Sci. 31, 463-476 (2000). doi:10.1016/S0021-8502(99)00536-4

41. A. Weber, K. Willeke, R. Marchioni, T. Myojo, R. McKay, J. Donnelly, F. Liebhaber, Aerosol penetration and leakage characteristics of masks used in the health care industry. Am. J. Infect. Control 21, 167-173 (1993). doi:10.1016/01966553(93)90027-2 Medline

42. F. Drewnick, J. Pikmann, F. Fachinger, L. Moormann, F. Sprang, S. Borrmann, Aerosol filtration efficiency of household materials for homemade face masks: Influence of material properties, particle size, particle electrical charge, face velocity, and leaks. Aerosol Sci. Technol. 55, 63-79 (2021). doi:10.1080/02786826.2020.1817846

43. J. M. Courtney, A. Bax, Hydrating the respiratory tract: An alternative explanation why masks lower severity of COVID-19. Biophys. J. 120, 994-1000 (2021). doi:10.1016/i.bpj.2021.02.002 Medline

44. S. Asadi, A. S. Wexler, C. D. Cappa, S. Barreda, N. M. Bouvier, W. D. Ristenpart, Aerosol emission and superemission during human speech increase with voice loudness. Sci. Rep. 9, 2348 (2019). doi:10.1038/s41598-019-38808-z Medline

45. R. Wölfel, V. M. Corman, W. Guggemos, M. Seilmaier, S. Zange, M. A. Müller, D. Niemeyer, T. C. Jones, P. Vollmar, C. Rothe, M. Hoelscher, T. Bleicker, S. Brünink, J. Schneider, R. Ehmann, K. Zwirglmaier, C. Drosten, C. Wendtner, Virological assessment of hospitalized patients with COVID-2019. Nature 581, 465-469 (2020). doi:10.1038/s41586-020-2196-x Medline

46. C. J. Worby, H.-H. Chang, Face mask use in the general population and optimal resource allocation during the COVID-19 pandemic. Nat. Commun. 11, 4049 (2020). doi:10.1038/s41467-020-17922-x Medline

47. L. Tian, X. Li, F. Qi, Q.-Y. Tang, V. Tang, J. Liu, Z. Li, X. Cheng, X. Li, Y. Shi, H. Liu, L.$\mathrm{H}$. Tang, Harnessing peak transmission around symptom onset for nonpharmaceutical intervention and containment of the COVID-19 pandemic. Nat. Commun. 12, 1147 (2021). doi:10.1038/s41467-021-21385-z Medline

48. R. O. J. H. Stutt, R. Retkute, M. Bradley, C. A. Gilligan, J. Colvin, A modelling framework to assess the likely effectiveness of facemasks in combination with 'lock-down' in managing the COVID-19 pandemic. Proc. Math. Phys. Eng. Sci. 476, 20200376 (2020). doi:10.1098/rspa.2020.0376 Medline

49. K. A. Prather, C. C. Wang, R. T. Schooley, Reducing transmission of SARS-CoV-2. Science 368, 1422-1424 (2020). doi:10.1126/science.abc6197 Medline

50. S. Chang, E. Pierson, P. W. Koh, J. Gerardin, B. Redbird, D. Grusky, J. Leskovec, Mobility network models of COVID-19 explain inequities and inform reopening. Nature 589, 82-87 (2021). doi:10.1038/s41586-020-2923-3 Medline

51. S. A. Kemp, B. Meng, I. A. T. M. Ferriera, R. Datir, W. T. Harvey, G. Papa, S. Lytras, D. A. Collier, A. Mohamed, G. Gallo, N. Thakur, The COVID-19 Genomics UK (COGUK) Consortium, A. M. Carabelli, J. C. Kenyon, A. M. Lever, A. De Marco, C. Saliba, K. Culap, E. Cameroni, L. Piccoli, D. Corti, L. C. James, D. Bailey, D. L. Robertson, R. K. Gupta, Recurrent emergence and transmission of a SARS-CoV-2 spike deletion H69/V70. bioRxiv 2020.12.14.422555 [Preprint]. 8 March 2021. https://doi.org/10.1101/2020.12.14.422555.

52. L. J. Radonovich Jr., M. S. Simberkoff, M. T. Bessesen, A. C. Brown, D. A. T. Cummings, C. A. Gaydos, J. G. Los, A. E. Krosche, C. L. Gibert, G. J. Gorse, A.-C. Nyquist, N. G. Reich, M. C. Rodriguez-Barradas, C. S. Price, T. M. Perl; ResPECT investigators, N95 respirators vs medical masks for preventing influenza among health care personnel: A randomized clinical trial. JAMA 322, 824-833 (2019). doi:10.1001/jama.2019.11645 Medline

53. O. T. Price, B. Asgharian, F. J. Miller, F. R. Cassee, R. de Winter-Sorkina, "Multiple Path Particle Dosimetry model (MPPD v1.0): A model for human and rat airway particle dosimetry," Rijksinstituut voor Volksgezondheid en Milieu (RIVM) rapport 650010030 (RIVM, 2002).

54. Y. Lyu, K. Zhang, F. Chai, T. Cheng, Q. Yang, Z. Zheng, X. Li, Atmospheric sizeresolved trace elements in a city affected by non-ferrous metal smelting: Indications of respiratory deposition and health risk. Environ. Pollut. 224, 559-571 (2017). doi:10.1016/i.envpol.2017.02.039 Medline

55. C.-C. Chen, K. Willeke, Aerosol penetration through surgical masks. Am. J. Infect. Control 20, 177-184 (1992). doi:10.1016/S0196-6553(05)80143-9 Medline

56. Y. Qian, K. Willeke, S. A. Grinshpun, J. Donnelly, C. C. Coffey, Performance of N95 respirators: Filtration efficiency for airborne microbial and inert particles. Am. Ind. Hyg. Assoc. J. 59, 128-132 (1998). doi:10.1080/15428119891010389 Medline

57. A. Bałazy, M. Toivola, A. Adhikari, S. K. Sivasubramani, T. Reponen, S. A. Grinshpun, Do N95 respirators provide 95\% protection level against airborne viruses, and how adequate are surgical masks? Am. J. Infect. Control 34, 51-57 (2006). doi:10.1016/i.aiic.2005.08.018 Medline

58. B. U. Lee, M. Yermakov, S. A. Grinshpun, Filtering efficiency of N95-and R95-type facepiece respirators, dust-mist facepiece respirators, and surgical masks operating in unipolarly ionized indoor air environments. Aerosol Air Qual. Res. 5 25-38 (2005). doi:10.4209/aagr.2005.06.0003

59. S.-A. Lee, S. A. Grinshpun, T. Reponen, Respiratory performance offered by N95 respirators and surgical masks: Human subject evaluation with $\mathrm{NaCl}$ aerosol representing bacterial and viral particle size range. Ann. Occup. Hyg. 52, 177-185 
(2008). doi:10.1093/annhyg/men005 Medline

60. M. L. Pöhlker, O. O. Krüger, J.-D. Förster, T. Berkemeier, W. Elbert, J. FröhlichNowoisky, U. Pöschl, C. Pöhlker, G. Bagheri, E. Bodenschatz, J. A. Huffman, S. Scheithauer, E. Mikhailov, Respiratory aerosols and droplets in the transmission of infectious diseases. arXiv:2103.01188v3 [physics.med-ph] (8 April 2021).

\section{ACKNOWLEDGMENTS}

The authors would like to thank the reviewers for the very helpful feedbacks. This study was supported by the Max Planck Society (MPG). Funding: Y.C. thanks the Minerva Program of the MPG. Author contributions: Y.C. and H.S. designed and led the study. H.S., Y.C. and N.M. performed the research. U.P. and M.O.A. discussed the results. C.W., S.R. and P.W. commented on the manuscript. Y.C., H.S. and U.P. wrote the manuscript with inputs from N.M. and all coauthors. Competing interests: Authors declare no competing interests. Data and materials availability: The data and code to generate the results in the manuscript are freely available on (31). All data are available in the main text or the supplementary materials. This work is licensed under a Creative Commons Attribution 4.0 International (CC BY 4.0) license, which permits unrestricted use, distribution, and reproduction in any medium, provided the original work is properly cited. To view a copy of this license, visit https://creativecommons.org/licenses/by/4.0/. This license does not apply to figures/photos/artwork or other content included in the article that is credited to a third party; obtain authorization from the rights holder before using such material.

\section{SUPPLEMENTARY MATERIALS}

science.sciencemag.org/cgi/content/full/science.abg6296/DC1

Supplementary Text

Figs. S1 to S14

Tables S1 to S6

References (32-60)

MDAR Reproducibility Checklist

18 January 2021; accepted 17 May 2021

Published online 20 May 2021

10.1126/science.abg6296 

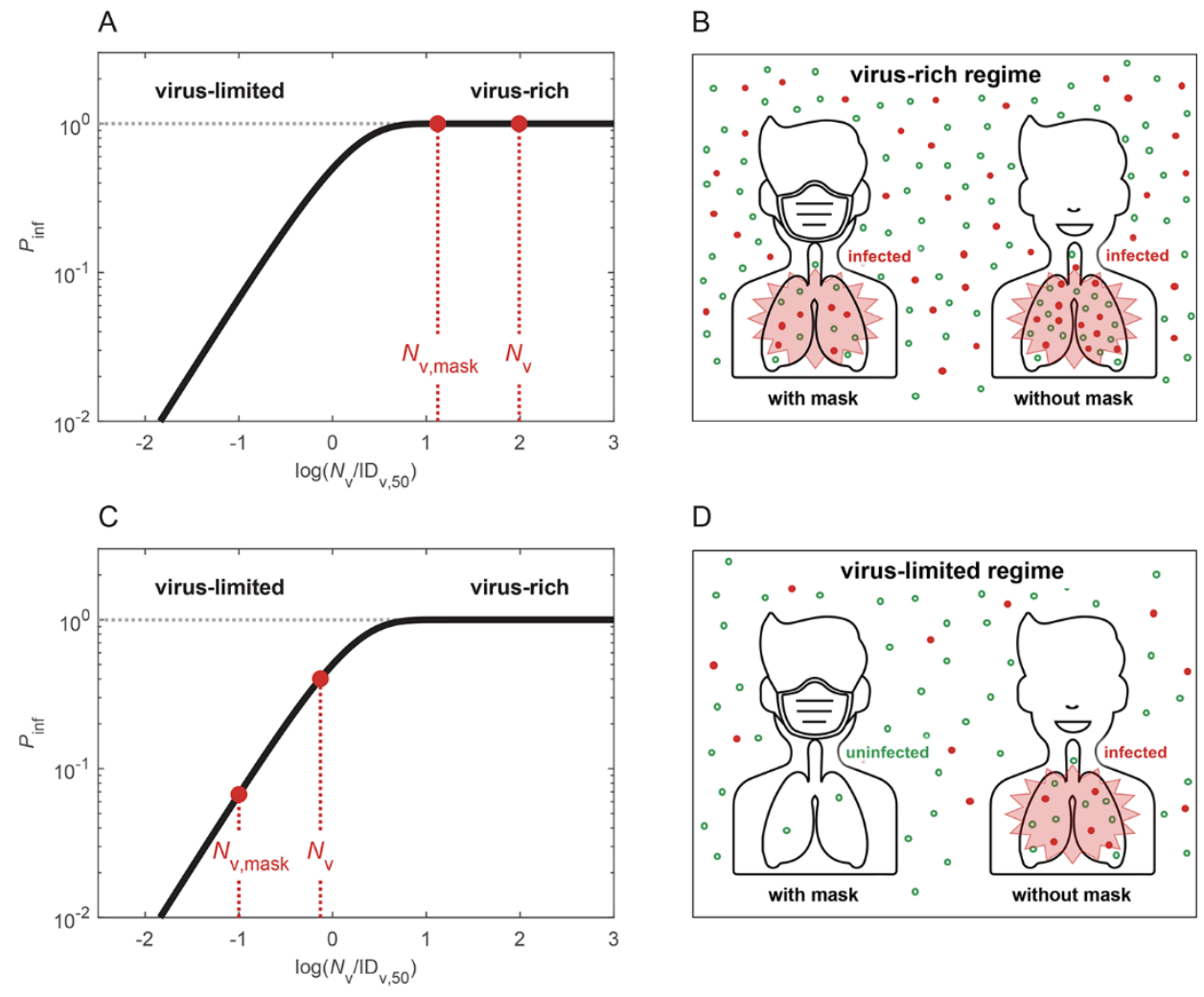

Fig. 1. Schematic illustration of different regimes of abundance of respiratory particles and viruses. The solid curve represents the infection probability $\left(P_{\text {inf }}\right)$ as a function of inhaled virus number $\left(N_{\mathrm{v}}\right)$ scaled by median infectious dose $I D_{v, 50}$ at which $P_{\text {inf }}=50 \%$. In the virus-rich regime ( $A$ and $\left.B\right)$, the concentration of airborne viruses is so high, that both number of viruses inhaled with or without mask $\left(N_{\mathrm{v}, \text { mask }}, N_{\mathrm{v}}\right)$ are much higher than ID $\mathrm{D}_{\mathrm{v}, 50}$ and $P_{\text {inf }}$ remains close to $\sim 1$ even if masks are used. In the virus-limited regime ( $C$ and D), $N_{v}$ and $N_{v, \text { mask }}$ are close to or lower than $I_{v, 50}$ and $P_{\text {inf }}$ decreases substantially when masks are used, even if the masks cannot prevent the inhalation of all respiratory particles. In panels B and D, the red dots represent respiratory particles containing viruses, and the open green circles represent respiratory particles without viruses. 

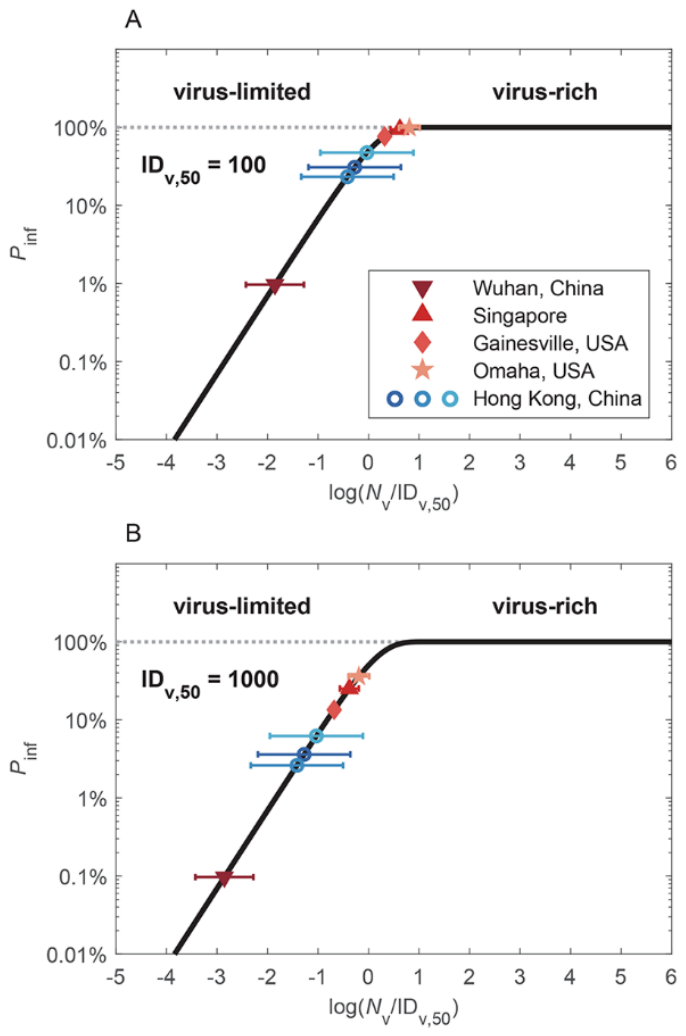

C

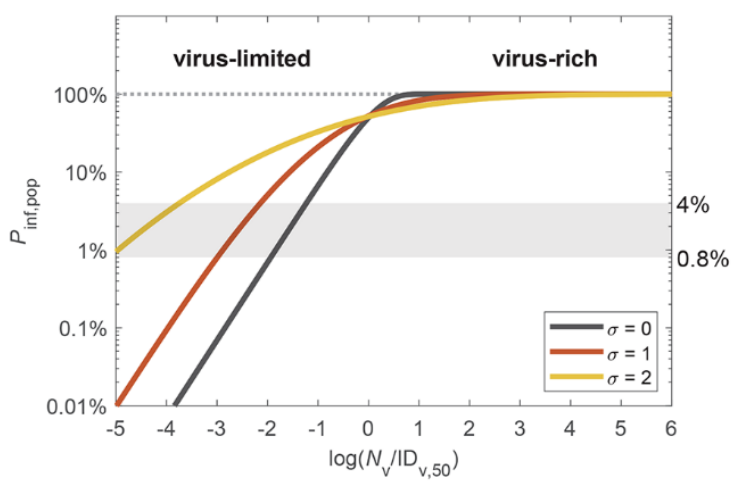

Fig. 2. Infection probabilities and abundance regimes of SARS-CoV-2 and other respiratory viruses. (A and $B$ ) Individual infection probabilities $\left(P_{\text {inf }}\right)$ plotted against inhaled virus number $\left(N_{\mathrm{v}}\right)$ scaled by characteristic median infectious doses of $I D_{v, 50}=100$ or 1000 , respectively. The colored data points represent the mean numbers of viruses inhaled during a 30-min period in different medical centers in China, Singapore, and the USA, according to measurement data of exhaled coronavirus, influenza virus, and rhinovirus numbers (blue circles) (11) and of airborne SARSCoV-2 number concentrations (red symbols) (15-18), respectively. The error bars represent one geometric standard deviation. (C) Population-average infection probability ( $\left.P_{\text {inf,pop }}\right)$ curves assuming lognormal distributions of $N_{v}$ with different standard deviations of $\sigma=0,1$, and 2 , respectively. The $x$-axis represents the mean value of $\log \left(N_{v} / / D_{v, 50}\right)$. The shaded area indicates the level of basic populationaverage infection probability, $P_{\text {inf,pop,o, for }}$ SARS-CoV-2 as calculated from the basic reproduction number for COVID-19 and estimated values of average duration of infectiousness and daily number of contacts. 

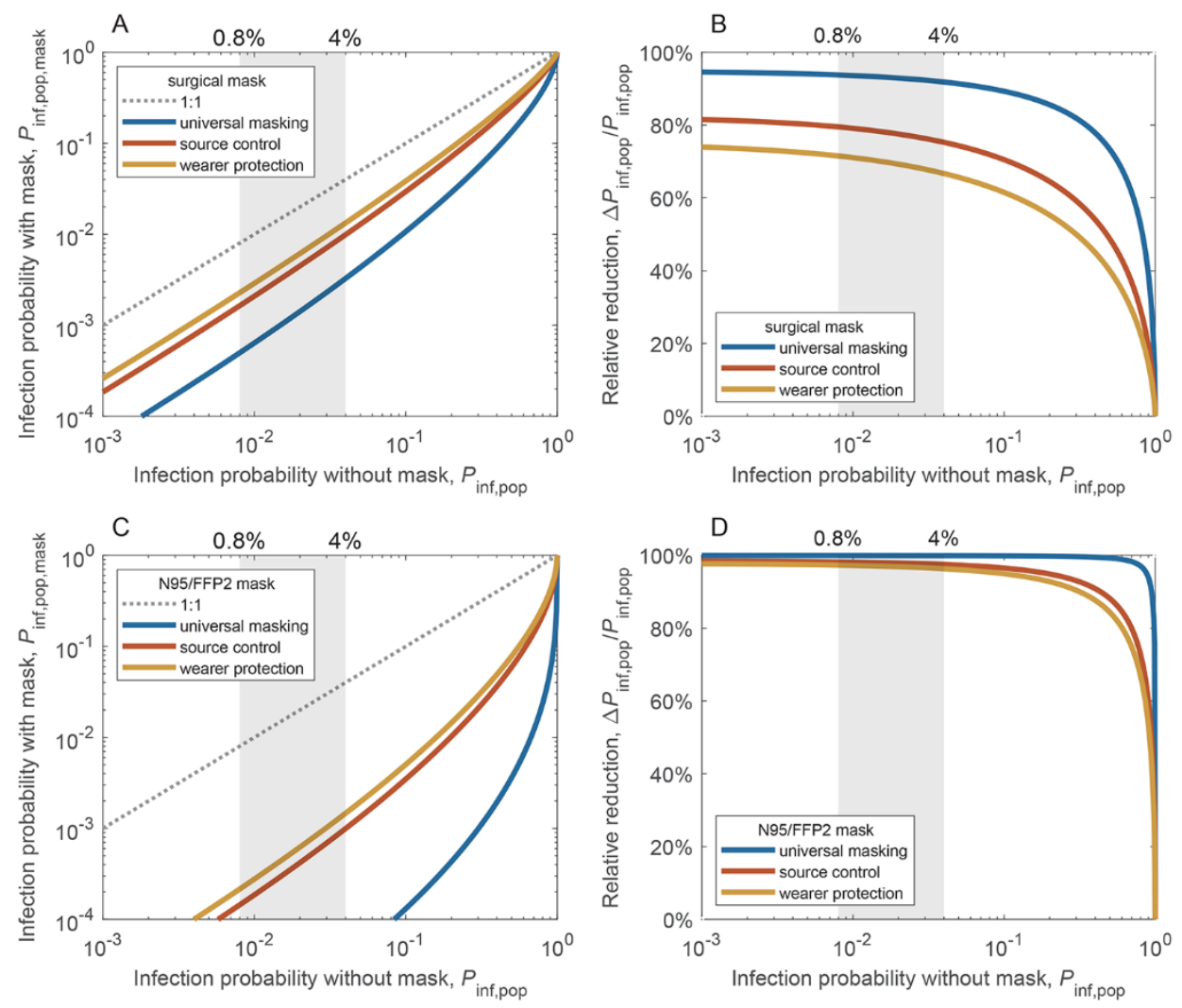

Fig. 3. Reduction of airborne transmission by face masks worn by infectious persons only (source control), by susceptible persons only (wearer protection), or by all persons (universal masking). (A) Population-average infection probability in case of mask use $\left(P_{\text {inf,pop,mask }}\right)$ plotted against infection probability without face masks $\left(P_{\text {inf,pop }}\right)$; and $(\mathrm{B})$ corresponding mask efficacy, i.e., relative reduction of infection probability, $\Delta P_{\text {inf,pop }} / P_{\text {inf,pop, }}$, plotted against $P_{\text {inf,pop }}$ for surgical masks. (C and $\mathrm{D}$ ) same as (A) and (B) but for N95/FFP2 masks; plots with linear scaling are shown in fig. S8. The lines represent the results obtained for source control (red line), wearer protection (yellow line), and the combination of both measures, i.e., universal masking (blue line) in a population where the virus exposure is lognormally distributed with a standard deviation of $\sigma=1$ (supplementary text, section S5). The shaded areas indicate the level of basic populationaverage infection probability, $P_{\text {inf,pop,o, }}$ corresponding to the basic reproduction number for COVID-19. 

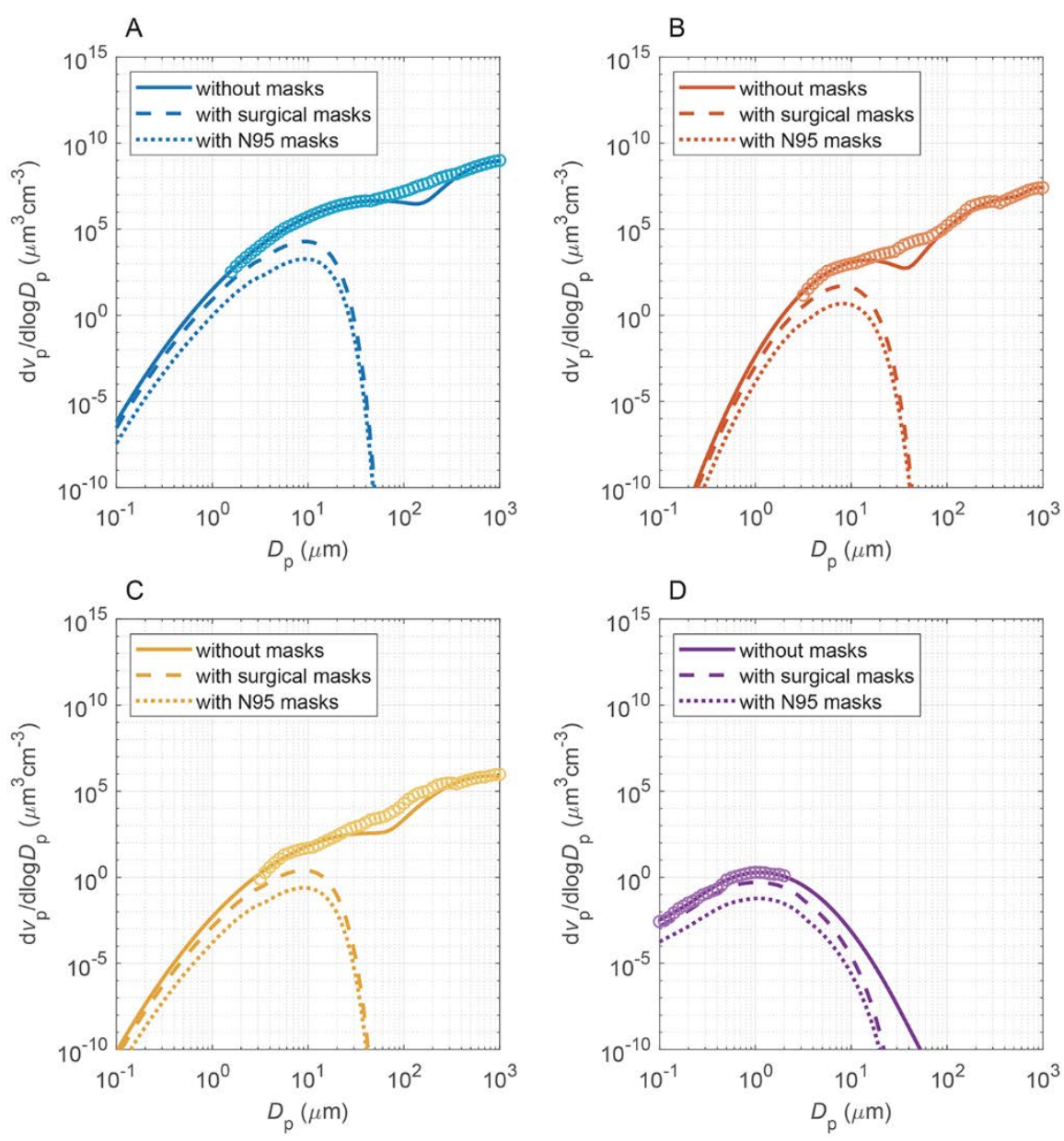

Fig. 4. Volume size distributions of respiratory particles emitted during different respiratory activities with and without masks. Sneezing (A), coughing (B), speaking (C), and breathing (D). The open circles are measurement data obtained without masks, and the solid lines are bi- or trimodal fits to the measurement data (25-27) (supplementary text, section S1.1). The dashed and dotted lines are obtained by scaling with the filter efficiency curves of surgical masks and of N95/FFP2 masks, respectively (supplementary text, section S3). The symbols $v_{p}$ and $D_{p}$ represent the volume concentration and diameter of respiratory particles, respectively, and $d v_{p} / d \log D_{p}$ represents the volume distribution function (supplementary text, section S1.1). 